\title{
Análise de habilidades motoras em alunos do sub-15 de futebol: uma revisão integrativa da literatura
}

\author{
Analyze of motor skills in soccer under-15 students: integrative literature review \\ Análisis de las habilidades motrices en estudiantes de fútbol menores de 15: una revisión \\ integrativa de la literatura
}

Recebido: 27/07/2021 | Revisado: 01/08/2021 | Aceito: 08/08/2021 | Publicado: 04/09/2021

\author{
Josias Moreira de Castro \\ ORCID: https://orcid.org/0000-0003-3046-0385 \\ Centro Universitário Santo Agostinho, Brasil \\ E-mail: josiasmcastro@gmail.com \\ Carlos Shuamke Ferreira dos Santos \\ ORCID: https://orcid.org/0000-0002-2819-7680 \\ Centro Universitário Santo Agostinho, Brasil \\ E-mail: c.shuanke@hotmail.com \\ Mozart Bastos de Oliveira Filho \\ ORCID: https://orcid.org/0000-0002-3758-9176 \\ Centro Universitário Santo Agostinho, Brasil \\ E-mail: mozartbastos@yahoo.com.br
}

\begin{abstract}
Resumo
O futebol é um esporte dinâmico, que exige de seus participantes diferentes habilidades e capacidades. As habilidades motoras se fazem muito presentes na modalidade de futebol, sendo realizado um conjunto de movimentos, onde se faz fundamental na prática esportiva e seleção de jovens talentos. Visto o número limitado de estudos de revisão que abordem a análise de habilidade motoras em jogadores de futebol, principalmente entre os mais jovens, presente estudo teve como objetivo avaliar habilidades motoras em alunos do sub-15 de futebol. Foi realizado uma revisão Integrativa com a utilização das bases de dados Scielo, Pubmed e Lilacs. Na análise foram consideradas publicações do período de 2010 a 2021, no idioma português, inglês e espanhol. Verificou-se que as habilidades motoras expressam um grau de coordenação dos movimentos, desenvolvendo mais rápido quando se estimula desde criança, um indivíduo pode ter diversas habilidades para cada função, sendo a habilidade esportiva necessária a todos os esportes A habilidade motora se mostrou importante para o futebol, inclusive na seleção de talentos e desenvolvimento pessoal. Novos estudos na área são necessários e devem fornecer mais evidências para atletas jovens de elite, pois especificamente esses primeiros anos na carreira de um jogador são cruciais para o desenvolvimento das habilidades.
\end{abstract}

Palavras-chave: Destreza motora; Futebol; Esportes juvenis.

\begin{abstract}
Soccer is a dynamic sport that requires different skills and abilities from its participants. Motor skills are very present in the sport of soccer, with a set of movements being performed, which is fundamental in sports practice and in the selection of young talents. Given the limited number of review studies that address the analysis of motor skills in soccer players, especially among younger people, this study aimed to assess motor skills in under-15 soccer students. An integrative review was carried out using the Scielo, Pubmed and Lilacs databases. The analysis considered publications from 2010 to 2021, in Portuguese, English and Spanish. It was found that motor skills express a degree of coordination of movements, developing faster when stimulated since childhood, an individual can have different skills for each function, being the sport skill necessary for all sports. Motor skill proved to be important for soccer, including talent selection and personal development. Further studies in the field are needed and should provide more evidence for elite young athletes, as specifically these early years in a player's career are crucial for skill development.
\end{abstract}

Keywords: Motor skill; Soccer; Youth sports.

\section{Resumen}

El fútbol es un deporte dinámico que requiere diferentes habilidades y habilidades de sus participantes. La motricidad está muy presente en el deporte del fútbol, con la realización de un conjunto de movimientos, fundamental en la práctica deportiva y la selección de jóvenes talentos. Dado el número limitado de estudios de revisión que abordan el análisis de las habilidades motoras en jugadores de fútbol, especialmente entre los más jóvenes, este estudio tuvo como objetivo evaluar las habilidades motoras en estudiantes de fútbol menores de 15 años. Se realizó una revisión integradora utilizando las bases de datos Scielo, Pubmed y Lilacs. El análisis consideró publicaciones de 2010 a 2021, en portugués, 
inglés y español. Se encontró que las habilidades motoras expresan un grado de coordinación de movimientos, desarrollándose más rápidamente cuando se estimulan desde la niñez, un individuo puede tener diferentes habilidades para cada función, siendo la habilidad deportiva necesaria para todos los deportes. La motricidad demostró ser importante para el fútbol, incluyendo selección de talentos y desarrollo personal. Se necesitan más estudios en el campo y deberían proporcionar más evidencia para los atletas jóvenes de élite, ya que específicamente estos primeros años en la carrera de un jugador son cruciales para el desarrollo de habilidades.

Palabras clave: Habilidad motora; Fútbol; Deportes juveniles.

\section{Introdução}

O futebol é o esporte com maior participação global. Mais de 200 milhões de pessoas de 203 nações são membros da Federação das Associações Internacionais de Futebol (Roth; Osbahr, 2018; Stubbe et al., 2015). Esse esporte é um grande fenômeno esportivo globalmente conhecido, e muito praticado por crianças, jovens e adultos. É um esporte que tem um desempenho muito grande no Brasil, no qual é conhecido como país do futebol. O futebol é um esporte dinâmico, que exige de seus componentes diferentes competências e habilidades. Habilidades motoras consistem em movimentos realizados com precisão, o marco da aprendizagem mostra que as alterações no comportamento obtidas ocorrem por meio da prática em repetidas tentativas. A complexidade da habilidade é tão influente no processo de aprendizagem quanto à experiência ou no nível de aprendizagem (Menezes et al., 2014).

Importante em muitos esportes, como no futebol (Ducan et al., 2021), o desenvolvimento motor pode ser influenciado por diversos fatores, sendo eles extrínsecos e intrínsecos, que, por sua vez, estão ligados principalmente a fatores ambientais, biológicos e genéticos. Os fatores intrínsecos estão associados diretamente aos biológicos e genéticos, são aqueles que não podem ser manipulados, e que são desenvolvidos desde a concepção, como por exemplo, o desenvolvimento do organismo. Esses fatores, entretanto, influenciam diretamente o desenvolvimento motor das crianças, pois definem pontos como a estatura e a amplitude do movimento, ambos podem ser modificados com a prática de atividade física. Os fatores extrínsecos estão relacionados principalmente à interação entre o ambiente, a atividade motora e os fatores de tarefa, como a sociedade em que a criança está inserida, contexto escolar e ambiente em que a criança vive (Silveira et al., 2014).

As habilidades motoras se fazem muito presentes na modalidade de futebol, se faz em um conjunto de movimentos, onde se faz fundamental na modalidade de futebol. Apresentam quatro fases da aprendizagem motora: Motora Reflexiva: os reflexos são as primeiras formas do movimento humano; Motora Rudimentar: os movimentos rudimentares são determinados de forma maturacional e caracterizam-se por uma sequência de aparecimento previsível; Motora Fundamental: são habilidades motoras fundamentais da primeira infância, são consequência da fase de movimentos rudimentares do período neonatal; Motora Especializada: trata-se de um período em que as habilidades estabilizadoras, locomotoras e manipulativas fundamentais são progressivamente refinadas, combinadas e elaboradas para o uso em situações crescentemente exigentes (Gallahuee; Ozmun, 2001).

Em um contexto geral o futebol não tem apenas o maior número de participantes em todo o mundo, é também o esporte mais estudado, com quase 15 mil citações listadas no Pubmed e quase 60\% a mais de artigos do que o próximo esporte mais estudado. Este vasto repositório de pesquisas de futebol mostra tendências em várias áreas principais e especialidades. O exame das tendências dos vários tópicos fornece esclarecimento sobre quais assuntos foram favorecidos e desfavorecidos, bem como quais tópicos ou dados demográficos foram negligenciados. (Kirkendall, 2020)

Um dos tópicos poucos abordados, no qual existe incipientes pesquisas são referentes a revisão habilidades motoras em jogares de futebol, principalmente entre os mais jovens (Moreira et al., 2016). Nessa perspectiva devido a poucas pesquisas na área e visto a importância da temática esse estudo buscou objetivo identificar através de uma revisão de literatura estudos que forneçam informações sobre habilidades motoras nos praticantes de futebol da categoria do sub 15 e analisar os níveis das 
habilidades motoras em praticantes de futebol.

\section{Metodologia}

O presente estudo trata-se de uma revisão integrativa qualitativa (Souza; Silva \& Carvalho 2010), onde baseou-se em estudos publicados nas bases de dados eletrônicas, utilizando trabalhos que abordassem o conhecimento sobre habilidades motoras em alunos de sub 15 de futebol, foram realizadas consultas e pesquisas científicas nas bases de dados SCIELO (Scientific Electronic Library Online), PUBMED (National Library of Medicine), LILACS (Literatura Latino - Americana e do Caribe em Ciências da Saúde). Na busca foram utilizados os seguintes termos provenientes do DeCS (Descritores em Ciências da Saúde) na língua portuguesa: "Destreza Motora", “Esportes", "Futebol" e "Esportes Juvenis"; inglesa, "Motor Skills" "Sports", "soccer", "Youth Sport", espanhola, "Destreza Motora”, "Deportes", "Fútbol”, "Deportes Juveniles". Os termos foram combinados com o operador booleano "AND"

A pesquisa iniciou no período dezembro de 2020 finalizando em junho de 2021, sendo selecionados artigos de ensaio clínico, estudo de coorte e transversal, nos idiomas português e inglês, a pesquisa foi limitada a trabalhos publicados no período de 2010 a 2021.

Dentro dos critérios de inclusão, estabeleceram-se artigos originais completos, no qual tivessem relação com o presente estudo, ou seja, que se adequassem à temática "Níveis de habilidades motoras em alunos praticantes de futebol". Após a seleção dos artigos, conforme os critérios de inclusão foram realizados a leitura de todos eles, dos quais foram retiradas informações de interesse, como também, foram investigadas suas listas de referências, visando encontrar artigos adicionais para a construção da revisão.

Como critérios de exclusão foram utilizados estudos sem determinação de metodologia clara. Foram excluídos artigos de revisão de literatura, teses e dissertações, assim como artigos cujo texto completo não fosse disponível nem mesmo após busca em biblioteca de referência, ou seja, aqueles cuja aquisição, por algum problema técnico, não fosse possível. Com os artigos selecionados, foram tabuladas as principais variáveis de interesse, como o tamanho da amostra, o objetivo, a metodologia, os parâmetros avaliados, os principais resultados. Os resultados dessa etapa exposto no Quadro 1:

A busca realizada apresentou 48 publicações na base de dados do Scielo, 220 publicações na base de dados Pubmed, 50 publicações na base de dados Lilacs. Inicialmente, foram encontrados 318 artigos. Desses 156foram incluídos pelo título, após leitura de títulos e resumos 136 estudos foram excluídos. 20 artigos foram incluídos para leitura complea, mais 5 foram excluídos por esta fora do escopo e 2 foram do objetivo proposto, restando 13 artigos que compuseram este estudo, o fluxograma da Figura 1 detalha todos os procedimentos de busca pelas pesquisas selecionadas para elaboração deste estudo.

Após o preenchimento do instrumento de análise, foi criado um quadro sinóptico para sintetizar e comparar os dados obtidos das publicações selecionadas para a análise. Os resultados foram analisados e discutidos de acordo com bibliografia selecionada, sendo expostos através de quadros quando foi necessário. 
Figura 1 - Fluxograma da seleção dos artigos (Prisma Flow).
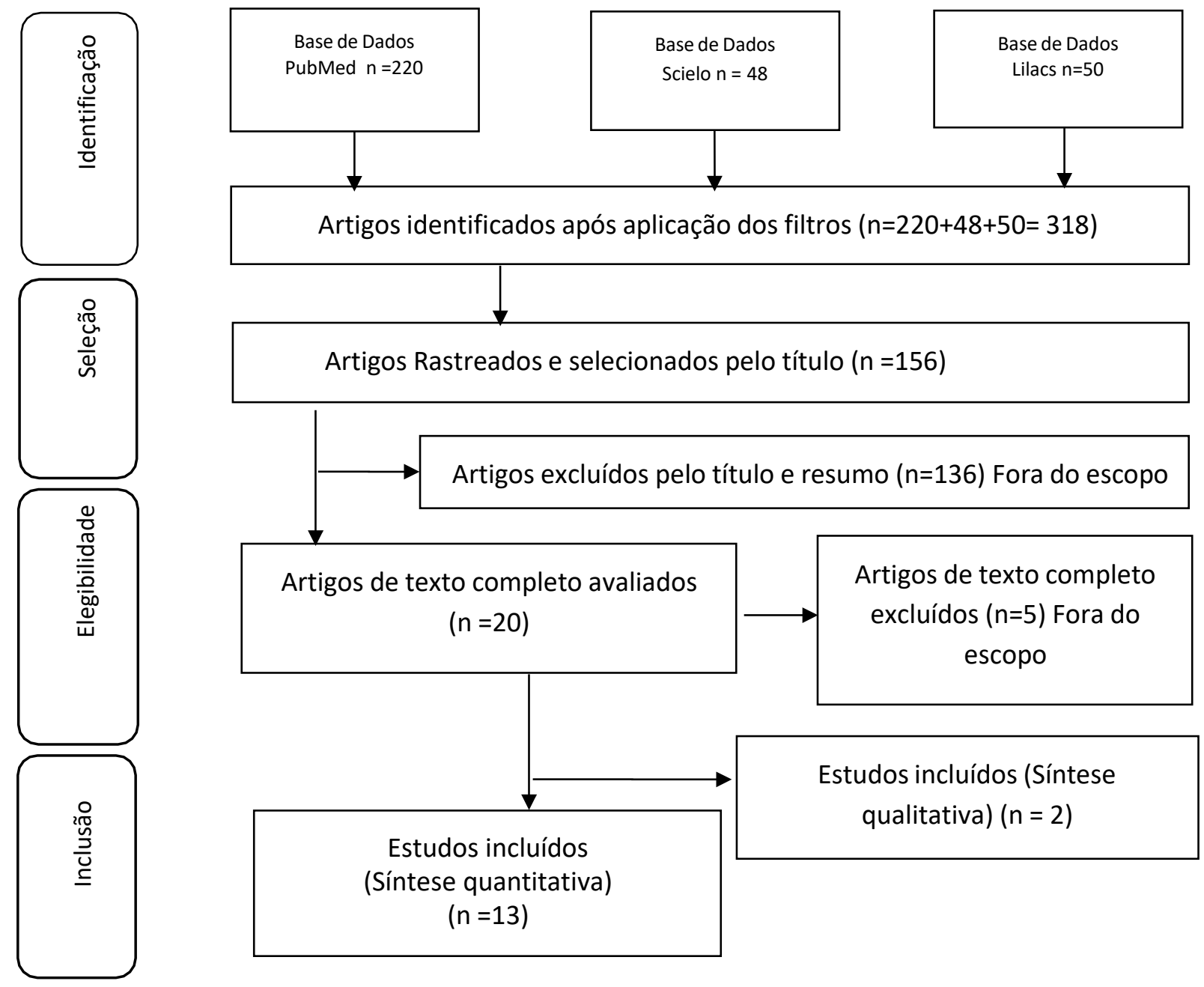

Fonte: Autores (2021).

\section{Resultados e Discussão}

Os resultados dessa pesquisa encontram-se a seguir e sua apresentação se dá através de e quadros e discussão dos dados encontrados. Na Quadro 1 estão dispostos os títulos e periódicos dos 12 artigos que fizeram parte da amostragem dessa pesquisa. Em suma os artigos mostraram a importância de habilidades motoras entres os praticantes de futebol sub-15 (Albuquerque et al. 2019; Bidaurrazaga-Letona et al., 2019; Jukic et al., 2019; Kokstejn; Musalek 2019; Menegassi et al., 2018; Prado et al., 2020; Reis et al., 2019; Roveda et al., 2020; Scharfen; Memmert, 2019; Silva et al., 2018; Spagnudo et al., 2013; Trecroci et al., 2015; Verburgh et al., 2016) que revela que o desenvolvimento de habilidades motoras para alunos de futebol mostrou-se eficaz, principalmente quando trabalhada desde cedo, o estudo elevou-se positivo para o início de práticas esportivas desde infância e adolescência, proporcionando maiores desempenhos, além de torná-los mais habilidosos durante a prática esportiva, aumentando a resistência, força e potência muscular dos praticantes de futebol. Mostrado na Quadro 2, no qual é mostrado os objetivos dos estudos metodologia de avaliação e principais resultados encontrados pelos autores.

Foi indicado que estudos habilidade motora é primordial os para seleção de jogadores nas categorias de base e identificação de futuros promissores profissionais de futebol, essa característica foi mencionado nos estudos (BidaurrazagaLetona et al., 2019; Jukic et al., 2019; Kokstejn; Musalek 2019; Menegassi et al., 2018; Prado et al., 2020; Reis et al., 2019; Roveda et al., 2020; Scharfen; Memmert, 2019; Spagnudo et al., 2013; Trecroci et al., 2015; Verburgh et al., 2016) que mostram 
que esse desempenho é importantes para serem identificados para jogar no clube, no qual habilidades são usadas em programas de escolha de talentos.

Entretanto, também foi indicado (Bidaurrazaga-Letona et al., 2019; Kokstejn; Musalek, 2019; Jukic et al., 2019) discrepância na seleção de talentos comparados a jogadores de idades inferiores, pois atletas sub-13 e sub-11, por exemplo são selecionados por habilidades motora, enquanto alguns casos de sub-15 podem ser selecionados por serem mais altos, mais pesados e mais fortes, focando assim em temas de maturação precoce.

Quadro 1 - Títulos, revistas e autores dos artigos selecionados na pesquisa.

\begin{tabular}{|c|c|c|c|}
\hline $\mathbf{N}^{0}$ do artigo & Título & Revista & Autores \\
\hline 01 & $\begin{array}{l}\text { Proposta de classificação multidimensional do } \\
\text { desempenho de jovens futebolista }\end{array}$ & $\begin{array}{l}\text { Revista Brasileira de } \\
\text { Ciência e Movimento }\end{array}$ & $\begin{array}{l}\text { Menegassi et al., } \\
2018\end{array}$ \\
\hline 02 & $\begin{array}{l}\text { Efeito do lùdico na melhora das habilidades motoras } \\
\text { em futebolista de } 12 \text { a } 16 \text { anos }\end{array}$ & Revista Buenos Aires & Silva et al, 2018 \\
\hline 03 & $\begin{array}{l}\text { Avaliação da influência do tempo de prática do futebol } \\
\text { sobre o desempenho motor de crianças }\end{array}$ & $\begin{array}{l}\text { Revista Brasileira de } \\
\text { Futsal e Futebol }\end{array}$ & Prado et al, 2020 \\
\hline 04 & $\begin{array}{l}\text { Avaliação da simetria e descarga de peso entre } \\
\text { membros inferiores de atletas de futebol de categoria } \\
\text { de base }\end{array}$ & $\begin{array}{l}\text { Revista Brasileira } \\
\text { Medicina e Esporte }\end{array}$ & $\begin{array}{l}\text { Spagnudo et al, } \\
2013\end{array}$ \\
\hline 05 & $\begin{array}{l}\text { Avaliação do desenvolvimento motor em crianças } \\
\text { praticantes de futebol e educação física escolar }\end{array}$ & Revista Hórus & Reis et al, 2019 \\
\hline 06 & $\begin{array}{l}\text { The relationship between fundamental motor skills } \\
\text { and game specific skills in } \\
\text { Elite young soccer players }\end{array}$ & $\begin{array}{l}\text { Journal of Physical } \\
\text { Education and Sport }\end{array}$ & $\begin{array}{l}\text { Kokstejn; } \\
\text { Musalek, } 2019\end{array}$ \\
\hline 07 & $\begin{array}{l}\text { Association between inhibitory control and tactical } \\
\text { performance of } \\
\text { Under- } 15 \text { soccer players }\end{array}$ & $\begin{array}{l}\text { Revista de Psicología } \\
\text { del Deporte }\end{array}$ & $\begin{array}{l}\text { Albuquerque et } \\
\text { al.,2019 }\end{array}$ \\
\hline 08 & $\begin{array}{l}\text { The relationship between cognitive functions and } \\
\text { sport-specific motor skills in elite youth soccer players }\end{array}$ & Frontiers in Psychology & $\begin{array}{l}\text { Scharfen; } \\
\text { Memmert, } 2019\end{array}$ \\
\hline 09 & $\begin{array}{l}\text { Progression in youth soccer: selection and } \\
\text { identification in youth soccer players aged } 13-15 \text { years }\end{array}$ & $\begin{array}{l}\text { The Journal of Strength } \\
\& \quad \text { Conditioning } \\
\text { Research }\end{array}$ & $\begin{array}{l}\text { Bidaurrazaga- } \\
\text { Letona et al., } \\
2019 .\end{array}$ \\
\hline 10 & $\begin{array}{l}\text { The importance of fundamental motor skills in } \\
\text { identifying differences in performance levels of u } 10 \\
\text { soccer players }\end{array}$ & Sports & Jukic et al., 2019 \\
\hline 11 & $\begin{array}{l}\text { Effect of chronotype on motor skills specific to soccer } \\
\text { in adolescent players }\end{array}$ & $\begin{array}{l}\text { Chronobiology } \\
\text { international, }\end{array}$ & $\begin{array}{l}\text { Roveda et al., } \\
2020 .\end{array}$ \\
\hline 12 & $\begin{array}{l}\text { Jump rope training: Balance and motor coordination in } \\
\text { preadolescent soccer players }\end{array}$ & $\begin{array}{l}\text { Journal of sports science } \\
\& \text { medicine, }\end{array}$ & $\begin{array}{l}\text { Trecroci et al., } \\
2015\end{array}$ \\
\hline 13 & $\begin{array}{l}\text { The key to success in elite athletes? Explicit and } \\
\text { implicit motor learning in youth elite and non-elite } \\
\text { soccer players }\end{array}$ & $\begin{array}{l}\text { Journal of sports } \\
\text { sciences }\end{array}$ & $\begin{array}{l}\text { Verburgh et al., } \\
2016\end{array}$ \\
\hline
\end{tabular}

Fonte: Autores (2021).

Isso pode levar a dispensa maior de atletas em idades maiores. Nesse sentido como afirma (Bidaurrazaga-Letona et al., 2019; Kokstejn; Musalek, 2019), os treinadores juvenis e projetos de seleção devem enfatizar o desenvolvimento adequado de habilidade motora. Os treinadores devem especialmente desenvolver e melhorar uma ampla gama de fundamentos habilidades motoras como blocos de construção de habilidades motoras mais complexas e difíceis, específicas do futebol, durante o longo 
prazo processo de treinamento, pois a força e a velocidade musculares são características fisiológicas centrais dos jogadores de futebol, que lhes permitem executar ações explosivas como correr, pular e chutar durante uma partida.

Por outro lado, a protocolos quantitativos para identificação de talentos no futebol se concentra em atributos atléticos genéricos dos esportes coletivos, como velocidade, força, agilidade e resistência, ao invés de habilidade. Na verdade, a grande maioria da ciência que ocorre com jogadores de futebol se concentra em como melhorar a velocidade, força e condicionamento físico, e como facilitar a recuperação rápida após jogos ou após uma lesão. Finalmente, muitos técnicos ainda acham que a avaliação de habilidades é seu domínio, e não dos cientistas. Mas, apesar dessas barreiras potenciais, o desenvolvimento de um protocolo abrangente para habilidades específicas do futebol pode melhorar significativamente a identificação e o desenvolvimento de talentos.

Quadro 2 - apresenta as tecnologias utilizadas no desenvolvimento de habilidades motoras em alunos de futebol sub 15 publicações e 8 artigos selecionados na pesquisa.

\begin{tabular}{|c|c|c|c|}
\hline Autor/Ano & Objetivo & Descrição da amostra e avaliação & Principais Resultados \\
\hline $\begin{array}{l}\text { Menegassi, et al, } \\
2018\end{array}$ & 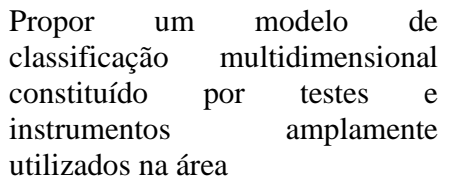 & $\begin{array}{l}\text { Testes específicos que avaliam o } \\
\text { desempenho técnico, tático, físico e } \\
\text { psicológico dos jogadores }\end{array}$ & $\begin{array}{l}\text { Mostrou-se eficaz para quantificar o } \\
\text { rendimento esportivo individual nas } \\
\text { variáveis: desempenho global com base } \\
\text { no grupo em que o jogador está inserido }\end{array}$ \\
\hline $\begin{array}{l}\text { Silva, et al, } \\
2018\end{array}$ & $\begin{array}{l}\text { Avaliar o efeito agudo da } \\
\text { ludicidade inserida no processo de } \\
\text { ensino de aprendizagem sobre a } \\
\text { eficácia do desempenho, agilidade } \\
\text { e velocidade }\end{array}$ & $\begin{array}{l}\text { Foram divididos em dois grupos GI } \\
\text { (lúdico) e GII (não lúdico) }\end{array}$ & $\begin{array}{l}\text { Os praticantes de futebol tiveram um } \\
\text { desempenho melhor das variáveis } \\
\text { agilidade e velocidade comparados ao } \\
\text { que não realizaram as atividades lúcidas }\end{array}$ \\
\hline $\begin{array}{l}\text { Spagnuolo, et } \\
\text { al, } 2013\end{array}$ & $\begin{array}{l}\text { Avaliar as características } \\
\text { funcionais e neuromusculares de } \\
\text { atletas de futebol da categoria de } \\
\text { base, no desempenho em saltos } \\
\text { verticais }\end{array}$ & $\begin{array}{l}\text { Foram realizados em duas plataformas } \\
\text { de força os seguintes saltos verticais: } \\
\text { salto em agachamento, salto em } \\
\text { contramovimento, saltos pliométricos } \\
\text { de } 40 \mathrm{~cm} \text { de altura }\end{array}$ & $\begin{array}{l}\text { Foram encontradas assimetrias entre os } \\
\text { membros biomecânicos. }\end{array}$ \\
\hline $\begin{array}{l}\text { Prado, et al, } \\
2020\end{array}$ & $\begin{array}{l}\text { Investigar se o tempo de prática de } \\
\text { futebol pode influenciar no } \\
\text { desempenho motor em crianças }\end{array}$ & $\begin{array}{l}\text { Participaram } 40 \text { meninos com faixa } \\
\text { etária entre } 07 \text { a } 10 \text { anos, divididos em } \\
2 \text { grupos, G1 grupo de iniciante } \\
\text { indivíduos com no máximo } 6 \text { meses de } \\
\text { futebol, G2 grupo de experiente com } \\
\text { no mínimo } 6 \text { meses e no máximo } 1 \text { ano } \\
\text { de experiência }\end{array}$ & $\begin{array}{l}\text { O desenvolvimento motor das crianças } \\
\text { mostrou-se bom, Porém o G2 por ter } \\
\text { mais tempo de prática apresentou melhor } \\
\text { resultados. }\end{array}$ \\
\hline Reis, et al, 2019 & $\begin{array}{l}\text { Verificar se existe diferenças no } \\
\text { desenvolvimento motor de } \\
\text { crianças que praticam futebol e } \\
\text { educação física escolar, com idade } \\
\text { de } 7 \text { a } 9 \text { anos }\end{array}$ & $\begin{array}{l}\text { Amostra foi construída por } 30 \\
\text { crianças, sendo } 15 \text { de cada grupo, } \\
\text { realizou quatro testes: equilíbrio em } \\
\text { marcha à retaguarda; saltos laterais; } \\
\text { saltos monopedais; e transposição }\end{array}$ & $\begin{array}{l}\text { Meninos tem coordenação motora } \\
\text { melhor que as meninas, e a modalidade } \\
\text { de futebol conseguiu melhor média do } \\
\text { quociente motor, embora não exista } \\
\text { diferença estatística significativa entre os } \\
\text { grupos no quociente motor }\end{array}$ \\
\hline $\begin{array}{l}\text { Kokstejn; } \\
\text { Musalek, } 2019\end{array}$ & $\begin{array}{l}\text { Investigar a relação entre as } \\
\text { habilidades motoras fundamentais } \\
\text { em jovens jogadores de futebol de } \\
\text { elite }\end{array}$ & $\begin{array}{l}24 \text { jogadores de futebol de elite com } \\
\text { idade média } 11,6 \pm 0,4 \text { anos foram } \\
\text { investigados quanto ao teste de drible } \\
\text { e arremesso, o teste de habilidades } \\
\text { motoras grossa } \\
\text { (TGMD-2) }\end{array}$ & $\begin{array}{l}\text { Os jogadores mostram baixo } \\
\text { desempenho em vários subtestes: golpear } \\
\text { uma bola estacionária, arremesso por } \\
\text { cima, rolar por baixo e salto horizontal. } \\
\text { Estes resultados demonstram a } \\
\text { necessidade de um certo nível de } \\
\text { habilidades motoras fundamentais finas e } \\
\text { grosseiras, a fim de adquirir habilidades } \\
\text { motoras específicas do jogo }\end{array}$ \\
\hline
\end{tabular}




\begin{tabular}{|c|c|c|c|}
\hline $\begin{array}{l}\text { Albuquerque } e t \\
\text { al.,2019 }\end{array}$ & $\begin{array}{l}\text { Examinar a relação entre as } \\
\text { funções cognitivas básicas e as } \\
\text { habilidades motoras específicas do } \\
\text { esporte em jogadores de futebol } \\
\text { juvenil de elite }\end{array}$ & $\begin{array}{l}15 \text { jogadores de futebol juvenil de elite } \\
\text { com idades entre 11-13 anos } \\
\text { realizaram uma bateria de teste } \\
\text { baseada em computador medindo a } \\
\text { janela de atenção, carga perceptual, } \\
\text { capacidade de memória de trabalho e } \\
\text { rastreamento de múltiplos objetos. } \\
\text { Outro conjunto de testes foi usado para } \\
\text { avaliar habilidades de velocidade e } \\
\text { habilidades técnicas específicas do } \\
\text { futebol (sprint, mudança de direção, } \\
\text { drible, controle de bola, chute e } \\
\text { malabarismo) }\end{array}$ & $\begin{array}{l}\text { A pontuação acumulada de todos os } \\
\text { testes cognitivos foi positivamente } \\
\text { relacionada à pontuação acumulada do } \\
\text { teste motor, que apoia a interação de } \\
\text { habilidades físicas e psicológicas. }\end{array}$ \\
\hline $\begin{array}{l}\text { Scharfen; } \\
\text { Memmert, } 2019\end{array}$ & $\begin{array}{l}\text { Investigar a associação entre o } \\
\text { controle inibitório e o desempenho } \\
\text { tático do jogadoras de futebol sub- } \\
15 .\end{array}$ & $\begin{array}{l}\text { Foram analisados dados de } 166 \\
\text { jogadores de futebol com menos de } 15 \\
\text { anos. O desempenho tático e o } \\
\text { controle inibitório foram } \\
\text { avaliado pelo Sistema de Avaliação } \\
\text { Tática no Futebol (FUT-SAT) e pelo } \\
\text { Teste Contínuo de Desempenho de } \\
\text { Conners } 2^{\circ} \text { versão (CPT-II) }\end{array}$ & $\begin{array}{l}\text { Os resultados revelaram que jogadores } \\
\text { com altas pontuações no desempenho } \\
\text { tático apresentaram } \\
\text { valores mais baixos do Tempo de reação } \\
\text { de impacto. Sugerindo que os jogadores } \\
\text { com melhores habilidades motoras } \\
\text { apresentaram uma melhor capacidade de } \\
\text { responder mais rápido em uma tarefa de } \\
\text { controle inibitório }\end{array}$ \\
\hline $\begin{array}{l}\text { Bidaurrazaga- } \\
\text { Letona, et al., } \\
2019 .\end{array}$ & $\begin{array}{l}\text { Identificar os fatores que são } \\
\text { importantes para a identificação e } \\
\text { seleção de jovens jogadores de } \\
\text { futebol. Com análise de habilidade } \\
\text { motoras }\end{array}$ & $\begin{array}{l}\text { Noventa e quatro adolescentes } \\
\text { jogadores de futebol de menores de } 13 \\
\text { anos e menores de } 15 \text { anos } \\
\text { participaram do estudo categorias } \\
\text { pertencentes a um clube profissional. } \\
\text { Medidas antropométricas, testes } \\
\text { físicos (sprint, agilidade, resistência e } \\
\text { salto) estado de maturidade (idade no } \\
\text { pico de velocidade de crescimento) } \\
\text { foram registrados ao longo de } 4 \\
\text { temporadas }\end{array}$ & $\begin{array}{l}\text { O melhor desempenho físico e as } \\
\text { melhorias observadas durante a } \\
\text { temporada no desempenho foram } \\
\text { considerados um dos principais fatores } \\
\text { para os jogadores sub - } 13 \text { continuarem } \\
\text { no clube. No grupo Sub15, embora o } \\
\text { tamanho corporal, maturação e } \\
\text { desempenho físico pareçam ser as } \\
\text { características mais importantes para } \\
\text { serem identificados para jogar no clube }\end{array}$ \\
\hline $\begin{array}{l}\text { Jukic et al., } \\
2019 .\end{array}$ & $\begin{array}{l}\text { Examinar as diferenças nas } \\
\text { habilidades motoras fundamentais } \\
\text { e capacidades de condicionamento } \\
\text { específico entre a classificação de } \\
\text { um treinador de jogadores de } \\
\text { futebol sub-10 }\end{array}$ & $\begin{array}{l}\text { Os jogadores de futebol sub-10 foram } \\
\text { avaliados usando o Teste de } \\
\text { Desenvolvimento Motor Grosso- } 2 \text {, } \\
\text { salto em distância em pé, sentar-se e } \\
\text { alcançar, diversos sprints e o teste de } \\
\text { condicionamento físico em vários } \\
\text { estágios de } 20 \mathrm{~m}\end{array}$ & $\begin{array}{l}\text { Os jogadores mostraram habilidade } \\
\text { motora, essas habilidades mostraram } \\
\text { potencial para identificar jovens } \\
\text { jogadores de futebol talentosos }\end{array}$ \\
\hline $\begin{array}{l}\text { Roveda } \text { et al., } \\
2020\end{array}$ & $\begin{array}{l}\text { Determinar o efeito do cronótipo e } \\
\text { habilidades motoras específicas do } \\
\text { futebol, especificamente se a } \\
\text { agilidade, a resistência aeróbia e a } \\
\text { potência explosiva diferem entre } \\
\text { os três cronótipos }\end{array}$ & $\begin{array}{l}141 \text { jogadores de futebol adolescentes } \\
\text { com idade menor de } 14 \text { anos } \\
\text { preencheram o Q Questionário } \\
\text { Morningness-Eveningness, } \\
\text { realizaram três testes (Sargent Jump } \\
\text { Test - SJT, Illinois Agility Test - IAT } \\
\text { e Teste de Corrida de } 6 \text { Minutos - } \\
6 \mathrm{MRT} \text { ) em uma sessão de treinamento } \\
\text { matutino e noturno (9h00 e 18h00). }\end{array}$ & $\begin{array}{l}\text { Em todos os testes, } \mathrm{p}<0,05) \text {, houve } \\
\text { melhor desempenho à noite do que na } \\
\text { sessão da manhã }(\mathrm{p}<0,05) \text {, e nenhuma } \\
\text { diferença no desempenho do teste foi } \\
\text { detectada para os tipos-N. Esses achados } \\
\text { reforçam a importância de uma } \\
\text { abordagem cronobiológica correta para o } \\
\text { treinamento esportivo }\end{array}$ \\
\hline $\begin{array}{l}\text { Tecroci et al., } \\
2020\end{array}$ & $\begin{array}{l}\text { Efeitos de um protocolo de } \\
\text { treinamento de curta duração } \\
\text { incluindo exercícios de pular } \\
\text { corda nas habilidades motoras e no } \\
\text { equilíbrio corporal de jovens } \\
\text { jogadores de futebol. }\end{array}$ & $\begin{array}{l}24 \text { Atletas com Idade inferior a } 12 \\
\text { anosVinte foram diviidos igualmente } \\
\text { em grupo Experimental (GE), as } \\
\text { crianças realizaram o treinamento de } \\
\text { JR no início da sessão de treinamento } \\
\text { e grupo controle (GC), executou } \\
\text { exercícios específicos para o } \\
\text { futebol. O teste de circuito de Harre } \\
\text { (HCT) e o teste de equilíbrio Y inferior } \\
\text { (YBT-LQ) foram selecionados para } \\
\text { avaliar a capacidade motora do } \\
\text { participante para avaliar }\end{array}$ & $\begin{array}{l}\text { As crianças que realizaram exercícios de } \\
\text { pular corda apresentaram diminuição } \\
\text { significativa de } 9 \% \text { no tempo de } \\
\text { execução do TCHNossos resultados } \\
\text { demonstraram que a prática de JR dentro } \\
\text { do treinamento regular de futebol } \\
\text { melhorou a coordenação motora geral e } \\
\text { o equilíbrio em jogadores de futebol pré- } \\
\text { adolescentes. Portanto, a inclusão da } \\
\text { prática de JR nas sessões regulares de } \\
\text { treinamento de futebol deve ser }\end{array}$ \\
\hline
\end{tabular}




\begin{tabular}{|c|c|c|c|}
\hline & & $\begin{array}{l}\text { unilateralmente o equilíbrio dinâmico } \\
\text { dos membros inferiores após } 8 \\
\text { semanas de treinamento. }\end{array}$ & $\begin{array}{l}\text { estimulada para melhorar as habilidades } \\
\text { motoras das crianças }\end{array}$ \\
\hline $\begin{array}{l}\text { Verburgh et al., } \\
2016\end{array}$ & $\begin{array}{l}\text { Fornecer informações sobre } \\
\text { aprendizagem motora explícita e } \\
\text { implícita em jogadores de futebol } \\
\text { juvenil com diferentes níveis de } \\
\text { especialização }\end{array}$ & $\begin{array}{l}27 \text { jogadores de futebol juvenil de elite } \\
\text { e } 25 \text { jogadores de futebol não de elite } \\
\text { (com idades entre 10-12) realizaram } \\
\text { uma tarefa de tempo de reação em } \\
\text { série }\end{array}$ & $\begin{array}{l}\text { Em particular, durante a aprendizagem } \\
\text { motora implícita, o futebol juvenil de } \\
\text { elite apresentou tempo de reação em } \\
\text { série mais rápidos na fase inicial de } \\
\text { aprendizagem e atingiu o desempenho da } \\
\text { assíntota mais cedo }\end{array}$ \\
\hline
\end{tabular}

Fonte: Autores (2021).

Bidaurrazaga-Letona et al., 2019; Jukic et al., 2019; Spagnudo et al., 2013; Trecroci et al., 2015 e Verburgh et al., 2016 mostraram que os melhores jogadores em partidas também têm maior habilidade, mas a importância da habilidade para o sucesso da partida não está refletida atualmente na ciência do futebol. Embora seja mais fácil medir as velocidades de sprint do que a habilidade motora em quase todas as espécies animais, incluindo humanos, essas medidas de desempenho.

É importante reforçar o treino de habilidade motoras em atletas de futebol sub-15, pois como e informado por alguns autores, o futebol é um dos esportes mais praticados entre os adolescentes e os jogadores precisam de habilidades técnicas, táticas e físicas para ter sucesso. Nesse contexto, a adolescência é a fase da vida em que essas habilidades, quando bem treinadas, atingem seu pico de desenvolvimento (Bidaurrazaga-Letona et al., 2019; Jukic et al., 2019; Spagnudo et al., 2013; Verburgh et al., 2016).

Outro dado importante mostrado por estudos dessa revisão (Albuquerque et al. 2019; Kokstejn; Musalek 2019; Menegassi et al., 2018; Roveda et al., 2020; Scharfen; Memmert, 2019; Trecroci et al., 2015; Verburgh et al., 2016) é que preciso haver uma mudança nos treinos de desenvolvimento motor habilidade pois , as habilidades técnicas são focadas em movimentos coordenativos específicos dos membros superiores e inferiores, o que pode não permitir que os jogadores com pouca idade, se beneficiem plenamente das atividades gerais entretanto são treinados Carregar, passar, chutar e driblar a bola representam habilidades técnicas cruciais e são elementos predominantes nos treinos regulares de futebol.

O chute de futebol é um bom exemplo de movimento discreto rápido com os membros inferiores, muito usado em diferentes esportes nos quais a velocidade e a precisão são muito importantes. Além disso, muitas vezes no futebol os dois pés são usados para chutar. No entanto, não se sabe com precisão como o desempenho do chute é influenciado por instruções que enfatizam a velocidade, precisão ou ambos.e descobriram que ao priorizar a precisão a velocidade da bola de chute diminuiu para 75\% para 85\% (Jukic et al., 2019; Kokstejn; Musalek 2019; Menegassi et al., 2018; Trecroci et al., 2015; Verburgh et al., 2016).

Além disso, como discutido por Jukic et al., 2019; Kokstejn; Musalek 2019; Menegassi et al., 2018; Prado et al., 2020; Reis et al., 2019; Roveda et al., 2020 e Trecroci et al., 2015; os jogadores adultos altamente qualificados praticavam atividades esportivas específicas não organizadas e organizadas (ou seja, partidas de futebol) na maior parte do tempo na infância. No entanto, esse modelo de desenvolvimento é muito específico e pode facilitar o aumento da taxa de evasão, especialmente nos estágios de pré-adolescência e adolescência. TRECROCI

Mesmo que não seja para ser profissional no futuro as habilidades motoras proporcionadas podem ser importantes na formação da pessoa desenvolvimento da pessoa. Prado et al. (2020) afirmam que o futebol tem influência na evolução gradual do repertório motor em crianças que praticam e que somam a prática esportiva juntamente com a maturação do indivíduo, futebol evidência positivamente no desenvolvimento motor das crianças, evolução gradual do repertório motor em pessoas que praticam esporte. A avaliação e o acompanhamento das competências implicadas no jogo de futebol são fundamentais por permitirem a criação de indicadores objetivos para diagnosticar o desempenho do jovem futebolista. Destacando a importância de oferecer 
oportunidades para o desenvolvimento e habilidades motoras fundamentais na infância e adolescência a fim de promover a superação de barreira de prática e desenvolvimento de habilidades mais complexas, além de compreender que as habilidades motoras fundamentais desenvolvidas envolvem não apenas atingir o estágio maduro, mas também proporcionar o aumento de diversidade (Menegassi et al., 2018).

Como limitação nesse estudo pode ser citada o princípio da reprodutibilidade, no qual diferentes métodos de avaliação da habilidade motora foram realizados, sendo difícil a análise geral de dados, além da consistência dos estudos.

\section{Conclusão}

Os estudos mostraram e revelaram a habilidades motoras em praticantes de futebol, sub -15, principalmente frente a manutenção no esporte. As habilidades motoras apresentam um grau relevante de coordenação de movimentos que surgem ao longo da vida, onde o ser humano pode ter diversas habilidades para cada função, trabalhando diversos movimentos e grandes cadeias musculares, consistindo em um conjunto de movimentos executados com exatidão e precisão. E no futebol o desenvolvimento motor e o trabalho do mesmo é bastante considerável, influenciando a maturação gradual do repertório motor, levando em conta todas as fases, considerando também aspectos genéticos, ambientais, e o trabalho em cima dessas habilidades motoras traz melhorias no rendimento esportivo deixando a criança mais preparada para realizar tal tarefa.

Este estudo tentou mostrar os níveis de habilidades motoras e a importância dela para realizar determinadas atividades e buscamos contribuir para o incentivo de um melhor desempenho nessas aquisições motoras. Destaca-se aqui a importância de novos estudos relacionados ao tema, pois ainda existe grande escassez sobre o mesmo. Mais estudos na área são necessários e devem fornecer mais evidências para atletas jovens de elite, pois especificamente esses primeiros anos na carreira de um jogador são cruciais para o desenvolvimento das habilidades do atleta.

\section{Referências}

Albuquerque, M. R., Gonzaga, A. D. S., Greco, P. J., \& Costa, I. T. D. (2019). Association between inhibitory control and tactical performance of under-15 soccer players. Revista de psicología del deporte, 28(1), 63-69.

Almeida, G., Gusmão, M., Rocha, F., Cunha, A., \& Silva, L. (2019). A motivação para a prática de futebol de campo: um estudo com jovens atletas. Rev.eletrônica nacional de educação física, 9(13), 02-12.

Aquino, M., Browne, R., Sales, M., \& Dantas, R. (2012) Psicomotricidade como ferramenta da educação física na educação infantil. Rev. Brasileira de futebol e futsal, 4(14), 245-257.

Baccin, E., Ramalho, M., \& Nobre, G. (2011): Desenvolvimento motor de crianças na perspectivas da família e da escola, Rev. Digital Buenos Aires - 158

Baldi, M., Neto, N., \& Santos, R, (2018): Efeito do número de jogadores na frequência e distribuição dos fundamentos técnicos em jogos reduzidos na iniciação ao futebol, Rev. Ciências e Saúde, 22(1), .27-32.

Bidaurrazaga-Letona, I., Lekue, J. A., Amado, M., \& Gil, S. M. (2019). Progression in youth soccer: Selection and identification in youth soccer players aged 13-15 years. The Journal of Strength \& Conditioning Research, 33(9), 2548-2558.

Coelho, Lavorato, V., Carvalho, F., \& Silva, D. (2018): Avaliação da técnica de futebolista da categoria sub-15 em diferentes ambientes de prática. Rev. Brasileira de futebol e futsal, 10(40), 572-576.

Duncan, M. J., Eyre, E. L., Noon, M. R., Morris, R., Doug Thake, C., Clarke, N. D., \& Cunningham, A. J. (2021). Actual and perceived motor competence mediate the relationship between physical fitness and technical skill performance in young soccer players. European Journal of Sport Science, (just-accepted), $1-20$.

Dumith, S., Ramires V., \& Souza, M. (2020): Aptidão física relacionada ao desenvolvimento motor em escolares de 7 a 15 anos. Rev. Brasileira educ. física e esporte, 24(1), 5-14.

Gallahue, D. L., Ozmun, J. C., \& Goodway, J. (2001) Compreendendo o Desenvolvimento Motor - 7 ed: Bebês, Crianças, Adolescentes e Adultos. $7^{\text {a }}$ edição. Porto Alegre. AMGH.

Gonçalves, L., Cruz G, et al. Caracterização dos jovens jogadores de futebol. (2016) Rev. Motricidade, 12

Kirkendall, D. T. (2020). Evolution of soccer as a research topic. Progress in Cardiovascular Diseases, 63(6), 723-729. 
Research, Society and Development, v. 10, n. 11, e42101018780, 2021

(CC BY 4.0) | ISSN 2525-3409 | DOI: http://dx.doi.org/10.33448/rsd-v10i11.18780

Kokstejn, J., \& Musalek, M. (2019). The relationship between fundamental motor skills and game specific skills in elite young soccer players. Journal of Physical Education and Sport, 19, 249-254

Jukic, I., Prnjak, K., Zoellner, A., Tufano, J. J., Sekulic, D., \& Salaj, S. (2019). The importance of fundamental motor skills in identifying differences in performance levels of U10 soccer players. Sports, 7(7), 178.

Menegassi. Vm, Rechenchosky. L, Borges. Ph \& Rinaldi. W. (2018): Proposta de classificação multidimensional do desempenho de jovens futebolista. Rev.Brasileira ciência e movimento, 45-57.

Menezes, R., Munomura, M., \& Marques, R. (2014): Especialização esportiva precoce e o ensino dos jogos coletivos de invasão. Rev. Movimento 20(1)

Neto. H. (2016): Composição corporal em atletas de bases das modalidades de futsal e futebol de campo, Revista saúde e pesquisa, 9(1), 127-135

Prado, R., \& Silveira, R. (2020). Avaliação da influência do tempo de prática do futebol sobre o desempenho motor de crianças. Revista Brasileira de Futsal e Futebol, 12(47), 39-45.

Reis, M., \& Wienhage, C. (2019): Avaliação do desenvolvimento motor em crianças praticantes de futebol e educação física escolar. Revista Brasileira de Fisiologia do Exercí cio, 16(4), 208-214.

Roth, T. S., \& Osbahr, D. C. (2018). Knee Injuries in Elite Level Soccer Players. American journal of orthopedics (Belle Mead, NJ), 47(10).

Roveda, E., Mulè, A., Galasso, L., Castelli, L., Scurati, R., Michielon, G., \& Montaruli, A. (2020). Effect of chronotype on motor skills specific to soccer in adolescent players. Chronobiology international, 37(4), 552-563.

Spagnuolo, D., \& Machado, F. (2013): Avaliação da simetria e descarga de peso entre membros inferiores de atletas de futebol da categoria de base. Rev. Bras. Med. Esporte, 19(6)

Silveira, R., Cardoso, F., \& Souza, C. (2014): Avaliação do desenvolvimento motor de escolares com três baterias motoras, Rev. Cinergis, 15(3).

Silva, L., \& Neto, P. (2018) Efeito lúdico na melhoria das habilidades motoras em futebolista de 12 a 16 anos. Rev. Buenos Aries, 23(243).

Sousa, A., Vilar, D., \& Almeida, R. (2010): A Coordenação motora no futebol, Rev.brasileira de futsal e futebol, 2(5).

Souza, M. T. D., Silva, M. D. D., \& Carvalho, R. D. (2010). Revisão integrativa: o que é e como fazer. Einstein (São Paulo), 8, 102-106.

Willrick, A \& Azevedo, C, (2009) Desenvolvimento motor na infância: influência dos fatores de risco se programas de intervenção, Revista Neurociências, $17(1), 51-56$

Moreira, L. P., Andrade-Souza, V. A., Vasconcellos, F., \& Albuquerque, M. R. (2016). Influência da maturação na capacidade força explosiva de futebolistas da categoria sub-15. Revista Brasileira de Futebol (The Brazilian Journal of Soccer Science), 8(1), 76-83.

Scharfen, H. E., \& Memmert, D. (2019). The relationship between cognitive functions and sport-specific motor skills in elite youth soccer players. Frontiers in psychology, 10, 817.

Trecroci, A., Cavaggioni, L., Caccia, R., \& Alberti, G. (2015). Jump rope training: Balance and motor coordination in preadolescent soccer players. Journal of sports science \& medicine, 14(4), 792.

Verburgh, L., Scherder, E. J. A., Van Lange, P. A. M., \& Oosterlaan, J. (2016). The key to success in elite athletes? Explicit and implicit motor learning in youth elite and non-elite soccer players. Journal of sports sciences, 34(18), 1782-1790. 